\title{
Brief compression-only cardiopulmonary resuscitation training video and simulation with homemade mannequin improves CPR skills
}

Gregory K. Wanner ${ }^{1,2^{*}}$, Arayel Osborne $e^{1}$ and Charlotte H. Greene ${ }^{3}$

\begin{abstract}
Background: Cardiopulmonary resuscitation (CPR) training has traditionally involved classroom-based courses or, more recently, home-based video self-instruction. These methods typically require preparation and purchase fee; which can dissuade many potential bystanders from receiving training. This study aimed to evaluate the effectiveness of teaching compression-only CPR to previously untrained individuals using our 6-min online CPR training video and skills practice on a homemade mannequin, reproduced by viewers with commonly available items (towel, toilet paper roll, t-shirt).
\end{abstract}

Methods: Participants viewed the training video and practiced with the homemade mannequin. This was a parallel-design study with pre and post training evaluations of CPR skills (compression rate, depth, hand position, release), and hands-off time (time without compressions). CPR skills were evaluated using a sensor-equipped mannequin and two blinded CPR experts observed testing of participants.

Results: Twenty-four participants were included: 12 never-trained and 12 currently certified in CPR. Comparing pre and post training, the never-trained group had improvements in average compression rate per minute (64.3 to 103. $9, p=0.006)$, compressions with correct hand position in $1 \mathrm{~min}$ (8.3 to 54.3, $p=0.002$ ), and correct compression release in $1 \mathrm{~min}(21.2$ to $76.3, p<0.001)$. The CPR-certified group had adequate pre and post-test compression rates (>100/min), but an improved number of compressions with correct release (53.5 to 94.7, $p<0.001$ ). Both groups had significantly reduced hands-off time after training. Achieving adequate compression depths (>50 mm) remained problematic in both groups. Comparisons made between groups indicated significant improvements in compression depth, hand position, and hands-off time in never-trained compared to CPR-certified participants. Inter-rater agreement values were also calculated between the CPR experts and sensor-equipped mannequin.

Conclusions: A brief internet-based video coupled with skill practice on a homemade mannequin improved compression-only CPR skills, especially in the previously untrained participants. This training method allows for widespread compression-only CPR training with a tactile learning component, without fees or advance preparation.

\footnotetext{
* Correspondence: gregorywa@pcom.edu

${ }^{1}$ Clinical Faculty, Department of Emergency Medicine, Christiana Care Health System, 4755 Ogletown-Stanton Road, Newark, DE 19718, USA

${ }^{2}$ Philadelphia College of Osteopathic Medicine, Philadelphia, PA 19131, USA

Full list of author information is available at the end of the article
} 


\section{Background}

Each year over 300,000 people in the United States experience out-of-hospital cardiac arrest [1]. Cardiopulmonary resuscitation (CPR) initiated by bystanders can significantly improve survival outcomes, however, only $46.1 \%$ of cardiac arrest victims initially receive CPR from a bystander [1-3]. To help simplify the steps of CPR, compression-only CPR was included in the 2010 American Heart Association (AHA) guidelines as an effective method for untrained bystanders [4-8].

CPR training has traditionally consisted of an instructor-led course lasting several hours and requiring a course fee. Unfortunately the planning, time commitment, and cost all have the potential to dissuade many people from receiving CPR training $[9,10]$. More recently, abbreviated training methods providing video instruction and practice on an inflatable mannequin have proven to be effective [11-15]. While instructor-led training is recommended, European guidelines suggest that self-instruction with hands-on practice appears to be an "effective alternative" [11].

Our goal was to evaluate the effectiveness of using an internet-based video along with a homemade practice mannequin, reproduced by participants, to teach the skills of compression-only CPR to previously untrained individuals.

\section{Methods}

\section{Study design}

This was a parallel-design study with pre and post training evaluations of CPR effectiveness.

\section{Participant recruitment and exclusion}

Employees, students, and visitors at the Philadelphia College of Osteopathic Medicine were recruited via electronic billboards, campus-wide emails, and word of mouth. Individuals either never previously formally trained in CPR ("untrained") or currently certified in CPR ("trained/certified") were eligible for inclusion. This study aimed to evaluate a brief training session on previously untrained individuals' CPR skills. The CPR certified group was included as a comparison group to evaluate the effects of our training, if any, on individuals judged to be competent in CPR, in relation to untrained individuals. Previously CPR-trained but not currently CPR certified individuals were excluded. Demographics of participants are included in Table 1.

\section{Intervention}

All participants viewed a 6-min CPR training video we produced consisting of basic information about compressiononly CPR, a CPR demonstration, instruction on producing a homemade CPR mannequin (CPR tool), and encouragement to practice along with the video [16]. The CPR tool
Table 1 Demographics and CPR experience of participants

\begin{tabular}{lll}
\hline Characteristic & $\begin{array}{l}\text { Untrained } \\
(N=12)\end{array}$ & $\begin{array}{l}\text { Trained/Certified } \\
(N=12)\end{array}$ \\
\hline Age, mean years (SD) & $28.1(12.3)$ & $25.8(4.0)$ \\
Male gender (\%) & 25.0 & 58.3 \\
Status (\%) & & \\
Medical student & 0 & 75.0 \\
Graduate student & 25.0 & 8.3 \\
Employee (non-clinical) & 33.3 & 0 \\
Visitor & 41.7 & 16.7 \\
Total time CPR certified (years) & - & 2.3 \\
Last CPR course (months ago) & - & 5.1 \\
Witnessed CPR, ever, \% & 16.7 & 33.3 \\
Performed CPR, ever, \% & 0 & 16.7 \\
\hline
\end{tabular}

was recreated by participants using common household items (towel, toilet paper roll, and t-shirt), provided to participants (Fig. 1). Our goal was to evaluate whether participants would be able to recreate and use a homemade CPR tool along with video instruction to improve CPR skills, rather than to extensively evaluate the CPR tool itself. Materials for the homemade CPR tool were chosen after subjectively evaluating several other commonly available items, including pillows and plastic bottles. We compared our homemade CPR tool to the CPR Anytime kit (AHA, Dallas, TX), which required approximately $35.5 \mathrm{~kg}$ of force to cause a "click" signaling adequate depth. With this compressive force on our homemade mannequin, an average of $46.6 \mathrm{~mm}$ of depth was attained during compressions.

\section{Outcome measures}

All participants were given an identical scenario in which "a man collapses in the classroom." Participants were allowed 1-min to "perform as if this were a real situation" and evaluated using a sensor-equipped CPR mannequin (ResusciAnne ${ }^{\odot}$ SkillReporter $^{\mathrm{TM}}$ ) before and after the training video. Additionally, two blinded CPRexperts (emergency physicians, one current and one former CPR instructor) viewed videos of participants performing CPR. The video viewing order was randomized, blinding the CPR experts to the group (untrained versus CPR certified) and also blinding to the pre or post-training status of study participants. The CPR experts observed for appropriately performed skills (compression rate, depth, and recoil), similarly to a traditional CPR class; however, the sensor-equipped mannequin's objective data was used for data analysis. Primary outcome measures included compression rate, compression depth, correct hand position, correct release, and total hands-off time during the 1-min testing period. Secondary outcome measures included participants' opinions about their willingness to perform compressions. Inter- 

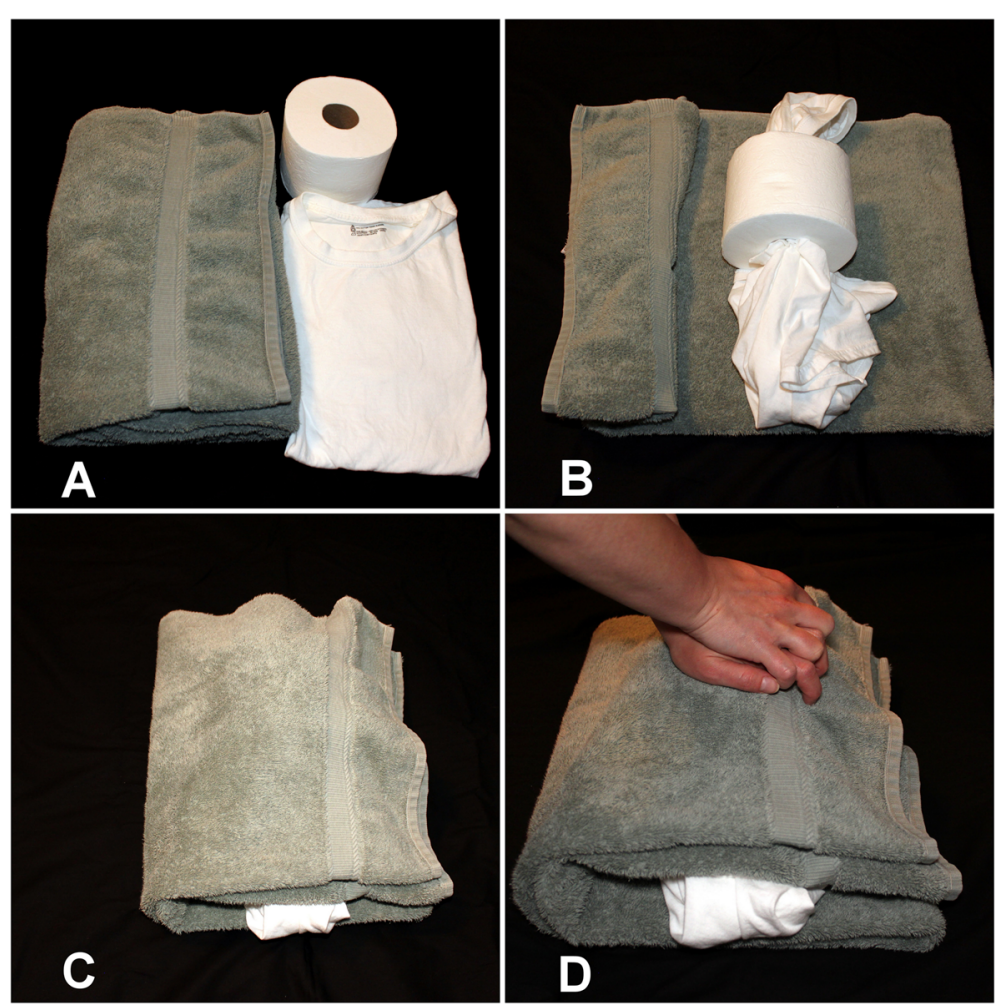

Fig. 1 a Materials to build CPR tool (towel, toilet paper, T-shirt); b T-shirt is placed within toilet paper tube; c Toilet paper roll/shirt are folded into towel; $\mathbf{d}$ Practicing compression-only CPR

rater reliability was also evaluated between the CPR experts and sensor-equipped mannequin.

\section{Statistical methods}

Sample size estimates were calculated using a power analysis to predict that a statistically significant difference could be detected at the alpha $=0.05$ level with a power of $80 \%$. Paired-difference t-test was used to evaluate the difference in performance of each group before and after training. Comparisons were made between groups using one-factor analysis of variance (ANOVA). Inter-rater reliability (Fleiss kappa) calculations were used to evaluate the CPR experts' and sensor-equipped mannequin's data [17]. Statistical analysis was performed using SAS software (SAS, Cary, NC).

\section{Results}

Comparing pre and post training, both the untrained group and trained/certified group showed improvements in several skills, reported in Table 2. In the untrained group, significant improvements were seen in compression rate, correct hand position, correct compression release/recoil, and hands off time. The trained/certified group had adequate compression rates $(>100 / \mathrm{min})$ before and after training. Comparing pre and post training, the trained/certified group had significant improvements in compressions with correct release, hands off time, and time to first compression. Compression depth remained inadequate $(<50 \mathrm{~mm})$ in both groups.

\section{Group comparisons}

ANOVA testing revealed several significant findings, reported in Table 3 . The compression rate per minute in the untrained group was significantly different both before and after training, compared to the trained/certified group. Although a statistically significant difference remained after training, both groups performed at adequate compression rates ( $>100$ per minute, per AHA guidelines). The number of compressions with correct hand position in $1 \mathrm{~min}$ was significantly different prior to training comparing untrained and trained/certified groups; however, after training the difference was no longer significant. Similarly, regarding both compression depth and hands-off time in $1 \mathrm{~min}$, prior to training there were significant differences between untrained and trained/certified groups; however, post-training comparisons of groups revealed a non-significant difference in compression depth and hands-off time.

\section{Evaluators' ratings}

Two blinded CPR experts viewed videos of each participant, observing participants' CPR performance for correct compression rate, depth, and full chest recoil; based on 
Table 2 Results before and after training in untrained and trained/certified groups

\begin{tabular}{|c|c|c|c|}
\hline & Pre-training & Post-training & $p$-value \\
\hline \multicolumn{4}{|l|}{ Untrained $(n=12)$} \\
\hline $\begin{array}{l}\text { Compression rate per } \\
\text { minute (SD) }\end{array}$ & $64.3(43.6)$ & $103.9(20.7)$ & 0.006 \\
\hline $\begin{array}{l}\text { Compression depth, mean in } \\
\mathrm{mm} \text { (SD) }\end{array}$ & $26.8(17.1)$ & $35.4(11.2)$ & 0.19 \\
\hline $\begin{array}{l}\text { Correct hand position, } \\
\text { compression \# in } 1 \text { min (SD) }\end{array}$ & $8.3(6.3)$ & $54.3(41.4)$ & 0.002 \\
\hline Correct release, in 1 min (SD) & $21.2(20.4)$ & $76.3(16.3)$ & $<0.001$ \\
\hline $\begin{array}{l}\text { Hands-off time, seconds in } \\
1 \text { min (SD) }\end{array}$ & $41.8(14.6)$ & $15.3(8.3)$ & $<0.001$ \\
\hline $\begin{array}{l}\text { Time to first compression, } \\
\text { seconds (SD) }\end{array}$ & $18.0(15.1)$ & $15.3(8.3)$ & 0.60 \\
\hline \multicolumn{4}{|l|}{ Trained/Certified $(n=12)$} \\
\hline $\begin{array}{l}\text { Compression rate per } \\
\text { minute (SD) }\end{array}$ & $119.3(15.2)$ & $120.7(12.8)$ & 0.65 \\
\hline $\begin{array}{l}\text { Compression depth, mean } \\
\text { in } \mathrm{mm}(\mathrm{SD})\end{array}$ & $46.3(10.4)$ & $43.8(9.8)$ & 0.02 \\
\hline $\begin{array}{l}\text { Correct hand position, } \\
\text { compression \# in } 1 \text { min (SD) }\end{array}$ & $41.5(25.7)$ & $59.3(49.3)$ & 0.15 \\
\hline Correct release, in 1 min (SD) & $53.5(19.3)$ & $94.7(15.4)$ & $<0.001$ \\
\hline $\begin{array}{l}\text { Hands-off time, seconds in } \\
1 \text { min (SD) }\end{array}$ & $28.8(7.1)$ & $11.4(5.3)$ & $<0.001$ \\
\hline $\begin{array}{l}\text { Time to first compression, } \\
\text { seconds (SD) }\end{array}$ & $17.4(7.8)$ & $11.1(2.5)$ & 0.02 \\
\hline
\end{tabular}

the AHA 2010 CPR guidelines. These items were also reported by the CPR mannequin's sensors. Inter-rater agreement was judged by calculating a Fleiss kappa value (к). Overall inter-rater agreement between the two human graders (CPR experts) for correctly performed skills was $65.9 \%(K=0.298)$. Overall inter-rater agreement between the CPR experts and the mannequin's computer was fair $(\kappa=0.335)$.

Table 3 Comparisons between groups, before and after training

\begin{tabular}{lllll}
\hline & $\begin{array}{l}\text { Pre/post } \\
\text { training }\end{array}$ & Untrained & $\begin{array}{l}\text { Trained/ } \\
\text { certified }\end{array}$ & $p$-value \\
\hline $\begin{array}{lllll}\text { Compression rate, } \\
\text { per minute (SD) }\end{array}$ & Pre & $64.3(43.6)$ & $119.3(15.2)$ & $<0.001$ \\
Compression depth, & Pre & $103.9(20.7)$ & $120.7(12.8)$ & 0.026 \\
mm (SD) & Post & $35.8(17.1)$ & $46.3(10.4)$ & 0.003 \\
Correct hand position, & Pre & $8.3(6.3)$ & $43.8(9.8)$ & 0.062 \\
per minute (SD) & Post & $54.3(41.4)$ & $59.3(49.3)$ & 0.790 \\
Hands-off time, seconds & Pre & $41.8(14.6)$ & $28.8(7.1)$ & 0.011 \\
in 1 min (SD) & Post & $15.3(8.3)$ & $11.4(5.3)$ & 0.193 \\
\hline
\end{tabular}

* Results of analysis of variance (ANOVA) testing

\section{Participants' opinions}

Surveys were completed by participants before and after training, including two questions to assess their opinions of performing CPR. Questions were answered using a fivepoint Likert scale $(1=$ Strongly Disagree, $5=$ Strongly Agree). Responding to the question "How comfortable do you feel in your ability to perform chest compressions?" both groups reported significant improvements in their self-perceived comfort levels. Answering the question "If you saw someone suddenly collapse, would you perform chest compressions, if needed?" showed non-significant increases in willingness to perform compressions. Results are reported in Table 4.

\section{Discussion}

Prior studies have shown the effectiveness of videobased brief CPR training compared to traditional CPR courses $[12,18,19]$. Our 6-min training video, production of homemade mannequin, and practice with this tool resulted in improvement in several aspects of CPR performance in both the untrained group and trained/ certified group. We noted improvements in compression rate, hand position, recoil, and hands-off time-especially in untrained participants-but difficulties with adequate depth in both groups. These results are similar to prior studies of brief CPR training, including brief classroom courses and video-based training lasting between $60 \mathrm{~s}$ and $22 \mathrm{~min}[13,14,20]$. Our study appears to be the first to include a homemade CPR mannequin with a self-directed instructional video; successfully adding a tactile component to home-based training. Additionally, participants' self-perceived abilities improved after training, but their willingness to perform compressions did not significantly change.

\section{Limitations}

Demographic differences were present between the two testing groups, including notable differences in gender, status (student, employee, visitor), and age ranges. It is unclear if these differences may have influenced our results. We did not evaluate CPR skill retention, however

Table 4 Responses to survey questions

\begin{tabular}{|c|c|c|c|}
\hline \multicolumn{4}{|c|}{ Survey question ( $5=$ Strongly Agree, $1=$ Strongly Disagree) } \\
\hline & Pre-training & Post-training & $p$-value \\
\hline \multicolumn{4}{|c|}{$\begin{array}{l}\text { "How comfortable do you feel in your ability to perform chest } \\
\text { compressions?" }\end{array}$} \\
\hline Untrained & 1.33 & 2.83 & 0.010 \\
\hline Trained/Certified & 2.67 & 3.75 & 0.008 \\
\hline \multicolumn{4}{|c|}{$\begin{array}{l}\text { "If you saw someone suddenly collapse, would you perform chest } \\
\text { compressions, if needed?" }\end{array}$} \\
\hline Untrained & 2.42 & 3.08 & 0.07 \\
\hline Trained/Certified & 3.75 & 3.83 & 0.59 \\
\hline
\end{tabular}


prior studies have suggested adequate retention after brief training [13, 19]. Participants performed identical testing scenarios before and after training, increasing familiarity with the testing mannequin, and potentially influencing results. The trained/certified group was included to help control for this effect, as this group has had prior experience with CPR and mannequin use, allowing a better understanding of the true effect of training on previously untrained participants. The interrater agreement between the two CPR experts was fairly low overall, highlighting the possible limitations of human graders' evaluations. To reduce potential for subjectivity, the objective data obtained from the sensorequipped CPR mannequin was used for statistical analysis; as was planned in the study design. The homemade mannequin/CPR tool was observed to be easily recreated by participants, however we did not formally evaluate participants' opinions of the CPR tool. Researchers observed that the toilet paper roll began to fatigue after several compressions, producing less recoil. Further research could focus on improving recoil in an equally convenient homemade CPR tool, improving compression depth, and directly comparing the homemade CPR tool to a commercially available CPR mannequin.

\section{Conclusions}

We feel it is possible to teach the basics of compressiononly CPR by combining a brief video and simulation with a homemade mannequin. Our method used a convenient internet-based video and a mannequin reproduced by viewers, requiring only an internet-enabled device and a towel, roll of toilet paper, and a t-shirt. While previously untrained participants appeared to benefit most from our training-performing similarly to CPR-certified participants in terms of hand position, depth, and hands-off time-the trained/certified participants also improved some skills; suggesting a possible role as a home-based refresher. Adequate compression depth remained problematic for both groups. These results suggest that using a brief online CPR video with a homemade mannequin has the ability to teach basic compression-only CPR skills with no additional cost or advance preparation.

\section{Acknowledgements}

We would like to thank Scott Berray and Drs. Joseph Faccio, Haley Spagnola, Matthew Stensland, and Barry Burton for their assistance with the project and training video; and Dr Bruce Stouch for assistance with statistical analysis.

\section{Funding}

This study was supported by a grant from the AMA Foundation Seed Grant Research Program (2011). Laerdal Medical loaned the use of a SkillReporter ${ }^{\top M}$ mannequin for the purposes of the study. These organizations had no role in the study design, data interpretation, or writing of the manuscript.

\section{Availability of data and material}

The datasets generated during and/or analysed during the current study available from the corresponding author on reasonable request. A small portion of the data (compression rate and depth) from an early data analysis was presented as a poster presentation/abstract at the American Heart Association Resuscitation Science Symposium on November 16, 2013 in Dallas, Texas USA.

\section{Authors' contributions}

GW, $A O$, and $C G$ all made substantial contributions to the design of the study. GW and AO led the production of the CPR training video. GW and CG acquired and interpreted the data. Data analysis was performed by GW and CG, with assistance of a statistician. All authors were involved in drafting of the manuscript and gave approval of the final version.

\section{Authors' information}

Gregory Wanner and Arayel Osborne are emergency physicians and clinical faculty at Christiana Care Health System. Charlotte Greene is a professor of physiology at Philadelphia College of Osteopathic Medicine. All authors have prior experience in pre-hospital emergency medical care.

\section{Competing interests}

The authors declare that they have no competing interests.

\section{Consent for publication}

Not applicable.

\section{Ethics approval and consent to participate}

This study was approved and judged to be exempt from written informed consent by the institutional review board at Philadelphia College of Osteopathic Medicine (protocol \#H10-052X). Participants gave verbal consent and their faces were obscured to hide identities during recording of the CPR testing videos.

\section{Author details}

${ }^{1}$ Clinical Faculty, Department of Emergency Medicine, Christiana Care Health System, 4755 Ogletown-Stanton Road, Newark, DE 19718, USA. ${ }^{2}$ Philadelphia College of Osteopathic Medicine, Philadelphia, PA 19131, USA. ${ }^{3}$ Department of Biomedical Sciences, Philadelphia College of Osteopathic Medicine, 4170 City Avenue, Philadelphia, PA 19131, USA.

Received: 18 August 2016 Accepted: 23 November 2016

Published online: 29 November 2016

\section{References}

1. Mozaffarian D, Benjamin EJ, Go AS, et al. Heart disease and stroke statistics - 2016 Update: a report from the American Heart Association. Circulation. 2016;133(4):e38-600.

2. Nakahara S, Tomio J, Icikawa M, et al. Association of bystander interventions with neurologically intact survival among patients with bystander-witnessed out-of hospital cardiac arrest in Japan. JAMA. 2015;314(3):247-54.

3. Hansen CM, Kragholm K, Pearson DA, et al. Association of bystander and first-responder intervention after Out-of-Hospital Cardiac Arrest in North Carolina, 2010-2013. JAMA. 2015;314(3):255-64.

4. Field JM, Hazinski MF, Sayre MR, et al. Part 1: executive summary: 2010 American heart association guidelines for cardiopulmonary resuscitation and emergency cardiovascular care. Circulation. 2010;122:S640-56.

5. Sayre MR, Berg RA, Cave DM, et al. Hands-only (compression-only) cardiopulmonary resuscitation: a call to action for bystander response to adults who experience out-of-hospital sudden cardiac arrest. Circulation. 2008:117:2162-7.

6. Hallstrom A, Cobb L, Johnson E, et al. Cardiopulmonary resuscitation by chest compression alone or with mouth-to-mouth ventilation. N Engl J Med. 2000;342(21):1546-53.

7. Bohm K, Rosenqvist M, Herlitz J, et al. Survival is similar after standard treatment and chest compression only in out-of-hospital bystander cardiopulmonary resuscitation. Circulation. 2007;116:2908-12.

8. Svensson L, Bohm K, Castren M, et al. Compression-only CPR or standard CPR in out-of-hospital cardiac arrest. N Engl J Med. 2010;363:434-42. 
9. Cariou G, Pelaccia T. Are they trained? Prevalence, motivations and barriers to CPR training among cohabitants of patients with a coronary disease. Intern Emerg Med. 2016; 27 Jun (epub ahead of print).

10. Potts J, Lynch B. The American Heart Association CPR Anytime Program: the potential impact of highly accessible training in cardiopulmonary resuscitation. J Cardiopulm Rehabil. 2006;26(6):346-54.

11. Greif R, Lockey AS, Conaghan P, et al. European Resuscitation Council Guidelines for Resuscitation 2015: Section 10. Education and implementation of resuscitation. Resuscitation. 2015;95:288-301.

12. Roppolo LP, Pepe PE, Campbell $L$, et al. Prospective, randomized trial of the effectiveness and retention of 30-min layperson training for cardiopulmonary resuscitation and automated external defibrillators: the American Airlines Study. Resuscitation. 2007;74(2):276-85.

13. Beskind DL, Stolz U, Thiede R, et al. Viewing a brief chest-compression-only CPR video improves bystander CPR performance and responsiveness in high school students: a cluster randomized trial. Resuscitation. 2016;104:28-33.

14. Jones I, Handley AJ, Whitfield R, Newcombe R, Chamberlain D. A preliminary feasibility study of a short DVD-based distance-learning package for basic life support. Resuscitation. 2007;75(2):350-6.

15. Reder $S$, Cummings $P$, Quan L. Comparison of three instructional methods for teaching cardiopulmonary resuscitation and use of an automatic external defibrillator to high school students. Resuscitation. 2006:69:443-53.

16. Wanner G, Berray S, Osborne A. DIY CPR: Learn CPR with a roll of toilet paper! [Video]. YouTube. https://www.youtube.com/watch?v=0-7EUhtXLRY. Published: December 16, 2012. Accessed 24 Nov 2016.

17. Geertzen J. Inter-Rater Agreement with multiple raters and variables. https://nlp-ml.io/jg/software/ira/. Published: 2012. Accessed 24 Nov 2016.

18. Lynch B, Einspruch EL, Nichol G, Becker LB, Aufderheide TP, Idris A. Effectiveness of a 30-min CPR self-instruction program for lay responders: a controlled randomized study. Resuscitation. 2005;67(1):31-43.

19. Einspruch EL, Lynch B, Aufderheide TP, Nichol G, Becker L. Retention of CPR skills learned in a traditional AHA Heartsaver course versus 30-min video selftraining: a controlled randomized study. Resuscitation. 2007:74(3):476-86.

20. Bobrow BJ, Vadeboncoeur TF, Spaite DW, et al. The effectiveness of ultrabrief and brief educational videos for training lay responders in handsonly cardiopulmonary resuscitation: implications for the future of citizen cardiopulmonary resuscitation training. Circ Cardiovasc Qual Outcomes. 2011;4(2):220-6

\section{Submit your next manuscript to BioMed Central and we will help you at every step:}

- We accept pre-submission inquiries

- Our selector tool helps you to find the most relevant journal

- We provide round the clock customer support

- Convenient online submission

- Thorough peer review

- Inclusion in PubMed and all major indexing services

- Maximum visibility for your research

Submit your manuscript at www biomedcentral com/submit 